\title{
Handgrip Strength of World Trade Center (WTC) Responders: The Role of Re-Experiencing Posttraumatic Stress Disorder (PTSD) Symptoms
}

\author{
Soumyadeep Mukherjee ${ }^{1}\left(\mathbb{D}\right.$, Sean Clouston ${ }^{2, * \mathbb{C}}$, Roman Kotov ${ }^{3}$, Evelyn Bromet ${ }^{3}$ and \\ Benjamin Luft ${ }^{4}$ (D) \\ 1 Community Health and Wellness, Health \& Physical Education Department, Rhode Island College, \\ Providence, RI 02908, USA; smukherjee@ric.edu \\ 2 Program in Public Health, Department of Family, Population, and Preventive Medicine, Renaissance School \\ of Medicine at Stony Brook University, Stony Brook, NY 11794, USA \\ 3 Department of Psychiatry, Renaissance School of Medicine at Stony Brook University, Stony Brook, \\ NY 11794, USA; roman.kotov@stonybrookmedicine.edu (R.K.); \\ evelyn.bromet@stonybrookmedicine.edu (E.B.) \\ 4 World Trade Center Health and Wellness Program Director, Department of Medicine, Renaissance School of \\ Medicine at Stony Brook University, Stony Brook, NY 11794, USA; Benjamin.Luft@stonybrookmedicine.edu \\ * Correspondence: sean.clouston@stonybrookmedicine.edu
}

Received: 18 February 2019; Accepted: 26 March 2019; Published: 29 March 2019

\begin{abstract}
Background: This study sought to examine whether handgrip strength (HGS), a measure of muscle strength and a biomarker of aging, was associated with post-traumatic stress disorder (PTSD) in a cohort of World Trade Center (WTC) responders at midlife. Methods: HGS was assessed utilizing a computer-assisted hand dynamometer administered to a consecutive sample of men and women $(n=2016)$ who participated in rescue and recovery efforts following the World Trade Center (WTC) attacks and subsequently attended monitoring appointments in Long Island, NY. PTSD symptom severity and depressive symptoms were assessed using the PTSD specific-trauma checklist (PCL-S) and the Patient Health Questionnaire (PHQ-9). General linear models were used to examine the association of WTC-related PTSD with HGS after adjusting for confounders. Results: The sample was at midlife (mean age $=53.3$ ) when assessed, and $91.3 \%$ were men. Nearly $10 \%$ of the sample had probable PTSD (PCL $\geq 44$ ) with concomitant depression (PHQ $\geq 10$ ), while 5.1\% had probable PTSD without depression. Average HGS was 57.4 lbs. (95\% confidence interval (95\% CI): 56.6-58.1) among men and $36.1 \mathrm{lbs}$. (95\% CI = 33.8-38.5) among women. Mean HGS of those with probable PTSD with concomitant depression was lower (45.9 lbs., 95\% CI = 43.6-48.2) than responders with only PTSD (49.1 lbs., 95\% CI = 46.0-52.4) and those without PTSD or depression (57.5 lbs., 95\% CI $=56.2-57.8$ ). Subdomain analyses of PTSD symptoms revealed that re-experiencing symptoms at enrollment ( $p=0.003$ ) was associated with lower HGS after adjusting for depressive symptoms and other confounders. Discussion: Results suggested that higher WTC-related PTSD symptom severity was associated with lower HGS. Results support ongoing work suggesting that PTSD may be associated with more rapid physical aging. The potential for developing interventions that might simultaneously improve physical and mental health in the aftermath of trauma may be considered.
\end{abstract}

Keywords: 9/11 disaster; handgrip strength; WTC responders; PTSD; depression; aging

\section{Introduction}

Hand grip strength (HGS) is an indicator of upper body strength that quantifies the amount of static force with which a person's hand can squeeze a dynamometer [1]. Often used as a marker of 
overall muscular strength, HGS is negatively associated with physical frailty [2]. Diminishing HGS is associated with muscle wasting and is commonly observed in older age, suggesting that it may act as a biomarker for aging. Poorer HGS is also associated with increased disability and mortality [3].

In addition to physical health, HGS has shown association with mental health outcomes. For example, a number of studies examining adults in midlife and older have reported that depressive symptoms were associated with HGS [4,5], while another study among Australians aged 85 years and older also found that lower HGS was associated with worse functional, psychological, and social health [3]. Additionally, higher HGS was shown to be associated with better cognitive performance among older participants with major depression, and those with bipolar disorder, as well as among healthy controls [6] and, in a second study maximal HGS was found to be associated with cognitive performance in the general population, and among those with schizophrenia [7].

Despite associations with a variety of health outcomes, to date no work has examined associations between HGS and symptoms of posttraumatic stress disorder (PTSD) in individuals who have experienced a severe trauma. Our recent work has suggested that PTSD may increase risk of cognitive aging [8] and physical functional limitations [9], suggestive of the potential for more rapid aging. This study therefore sought to determine whether weaker HGS is also associated with PTSD. Since PTSD is often comorbid with depression, we further examined whether the association, if any, of HGS with PTSD was magnified by the presence of depression. Lastly, since PTSD is a heterogeneous disorder, we further examined whether HGS had differential associations with PTSD symptom domains.

\section{Materials and Methods}

\subsection{Participants and Procedure}

The Centers for Disease Control and Prevention, in the year 2002, established a monitoring and treatment program for those who responded to the World Trade Center (WTC) terrorist attacks of 11 September 2001 by participating in rescue and recovery efforts. Since then, more than 33,000 responders have enrolled in the WTC general responder population (GRP) [10]. The WTC Wellness Program at Stony Brook University (SBU) monitors more than 8000 of these responders primarily residing on Long Island, NY. This SBU cohort is similar in terms of exposure, sex, and age to those enrolled in the GRP [10], with the majority being males (92.0\%), most of them working in law enforcement $(71.5 \%)$ during $9 / 11$, with an average age of 38.9 years at the time of the WTC attack. Most SBU responders $(85.0 \%)$ have continued to return to either Nassau or Suffolk county clinics within 18 months of their prior visit.

In 2016, the SBU WTC Wellness program began assessing responders' HGS as a part of their functional assessment. The current study includes a consecutive sample of responders $(n=2016)$ who were monitored between April 2016 and September 2017. The study was approved by the Stony Brook University Ethics Review Board (IRB approval No. 604113); responders provided informed, written consent. In comparison with the SBU population of responders who were eligible for research but did not complete the functional assessment, those who completed the functional assessment were 0.85 years younger $(p<0.001)$ and were less likely to be women $(p=0.004)$, but had similar occupations on 11 September $2001(p=0.115)$, showed similar levels of current PTSD $(p=0.521)$, and similar baseline PTSD Checklist (PCL) scores $(p=0.455)$.

\subsection{Assessment of HGS}

HGS was assessed for both hands only if responders did not self-report any trouble with their hands, shoulders, or wrists and if they felt that they would be able to safely complete the assessment. Vernier dynamometers were administered by trained healthcare providers to measure and record HGS among responders sitting upright in chairs with arm rests such that their elbow formed close to a right angle while they squeezed the dynamometer between their thumb and other fingers with maximum strength for $10 \mathrm{~s}$. Each responder completed two trials for each hand beginning with the left 
hand. Force was measured in pounds (lbs.) and recorded in a computer with Logger Pro software (Vernier®Software \& Technology, Beaverton, OR, USA). The data were exported as. csv files, cleaned and the maximum HGS was used for this study. The average of two trials were computed, followed by the average of two hands which was the outcome for this study.

\subsection{Assessment of PTSD Symptoms}

PTSD symptoms were assessed at each monitoring visit using the PTSD checklist, specific trauma version tailored to the WTC disaster (PCL-S trauma specific version) [11]. At each monitoring visit, respondents rated the extent to which they were bothered by 17 DSM-IV WTC-related PTSD symptoms during the past month on a scale from 1 (not at all) to 5 (extremely). The PCL has good internal consistency and convergent validity [12]. The total PCL score was used to categorize respondents into those who had or did not have probable WTC-related PTSD, using a cut-off of 44 [11]. Four PTSD symptom clusters were also analyzed: avoidance, hyperarousal, negative affect and re-experiencing symptoms.

\subsection{Assessment of Depressive Symptoms}

Symptoms of depression were measured by the Patient Health Questionnaire with nine items (PHQ-9). Probable depression was indicated by a PHQ-9 score of 10 or higher. WTC responders were categorized based on whether they had both probable PTSD and probable depression; probable PTSD without depression; or neither PTSD nor depression. Depression only group was not considered because of very few responders who had depression without PTSD symptoms.

\subsection{Covariates}

A number of variables that could be potentially associated with health and functional status were considered including age in years at the time of HGS assessment and gender. According to educational attainment, responders were categorized into those who did not finish high school, those who graduated high school, those with some college education, those with an undergraduate degree, and those who have been to graduate school. Race/ethnicity was categorized as non-Hispanic White, non-Hispanic Black, Hispanic, Asian, and others. Responders were categorized as single, married, and separated or divorced or widowed depending on their marital status. Current employment status was given as working full time, working part time, being disabled or on medical leave, retired, and laid off or unemployed. Annual household income (US\$) was categorized as 50,000 or less, more than 50,000 to 70,000 , more than 70,000 to 100,000 and higher than 100,000. According to their self-reported general health, responders had excellent, very good, good, fair, or poor general health. Responders' self-reported hand-dominance was taken into account to classify them as right-handed, left-handed, or ambidextrous.

Taking into account the severity of responders' exposure to the WTC disaster, four exposure groups-very high, high, intermediate, and low-were created based on the work of Wisnivesky et al. [13]. The very high exposure group comprised of those who worked more than 90 days at the WTC site, were exposed to the dust cloud due to the collapse of WTC buildings, and worked at least some time on the pile of debris. Rescue workers who were exposed to the dust cloud but either worked on-site less than 90 days or did not work on the debris pile, were categorized to have had high exposure. Workers with intermediate exposure were exposed to the dust cloud and either worked between 40 days and 90 days or did not work on the debris pile. Workers in the lowest exposure group worked less than 40 days on-site, were not exposed to dust from the collapse, and did not work on the debris pile. 


\subsection{Statistical Analysis}

Descriptive sample statistics, including means and standard deviations of maximum HGS were computed. Average of two runs from each hand was calculated followed by the average from both hands. Means and/or proportions were computed for all independent variables and covariates.

Linear regression was performed to examine bivariate associations of mean HGS with WTC-related probable PTSD and all other independent variables. Mean HGS were compared between different levels of each variable and $95 \%$ confidence intervals $(\mathrm{CI})$ were computed for the means. Estimates of regression coefficients and their respective p-values were reported. A two-tailed $\alpha=0.05$ was utilized to determine statistical significance. Multivariable general linear models were used to examine the association of WTC-related PTSD with HGS after adjusting for covariates.

In separate analyses, scores for individual PTSD domains were used to examine whether re-experiencing symptoms, avoiding situations reminiscent of the WTC event, negative changes in beliefs and feelings, or hyperarousal symptoms were associated with HGS, after adjusting for depression (PHQ-9) scores and other covariates.

\section{Results}

The mean age of the sample was 53.3 (SD: 7.9) years with a range from 35.1 to 85.0 at the time of their HGS assessment, and $91.3 \%$ were men (Table 1).

Table 1. Distribution of handgrip strength (HGS) with independent variables among World Trade Center (WTC) responders $(n=2023)$.

\begin{tabular}{|c|c|c|}
\hline Characteristics & Mean (SD)/Number (\%) & Mean HGS (lbs.) (95\% CI) \\
\hline Age in years & $53.3(7.9)$ & $55.5(54.8-56.3)$ \\
\hline \multicolumn{3}{|l|}{ Gender } \\
\hline Men & 1847 (91.3) & $57.4(56.6-58.1)$ \\
\hline Women & $176(8.7)$ & $36.1(33.8-38.5)$ \\
\hline \multicolumn{3}{|l|}{ Race/ethnicity } \\
\hline Non-Hispanic White 0 & $1613(85.8)$ & $56.2(55.3-57.0)$ \\
\hline Non-Hispanic Black 1 & $86(4.6)$ & $50.8(47.2-54.4)$ \\
\hline Hispanic 2 & $156(8.3)$ & $52.7(50.0-55.4)$ \\
\hline Asian 3 & $19(1.0)$ & $52.6(44.9-60.3)$ \\
\hline Other 4 & $7(0.4)$ & $47.9(35.3-60.5)$ \\
\hline \multicolumn{3}{|l|}{ Hand dominance } \\
\hline Right & $1721(85.1)$ & $55.4(54.6-56.2)$ \\
\hline Left & $208(10.3)$ & $55.5(53.1-57.8)$ \\
\hline Ambidextrous & $94(4.7)$ & $58.4(54.9-61.8)$ \\
\hline \multicolumn{3}{|l|}{ Marital status } \\
\hline Single & $107(5.3)$ & $49.9(46.6-53.1)$ \\
\hline Married & $1678(83.0)$ & $56.1(55.3-56.9)$ \\
\hline Separated/Divorced/Widowed & $238(11.8)$ & $53.8(51.6-56.0)$ \\
\hline \multicolumn{3}{|l|}{ Education } \\
\hline Did not finish high school & $55(2.8)$ & $51.6(47.0-56.1)$ \\
\hline Graduated high school & $349(17.8)$ & $53.5(51.7-55.3)$ \\
\hline Some college & $935(47.7)$ & $55.6(54.5-56.7)$ \\
\hline Undergraduate degree & $467(23.8)$ & $57.6(56.1-59.2)$ \\
\hline Graduate school & $155(7.9)$ & $55.0(52.3-57.7)$ \\
\hline \multicolumn{3}{|l|}{ Current employment status } \\
\hline Working full time & $1153(57.6)$ & $58.8(57.8-59.7)$ \\
\hline Working part time & $147(7.3)$ & $56.9(54.2-59.6)$ \\
\hline Disabled/on medical leave & $106(5.3)$ & $50.6(47.5-53.8)$ \\
\hline Retired & $572(28.6)$ & $50.1(48.7-51.4)$ \\
\hline Laid off/unemployed & $25(1.3)$ & $51.3(44.8-57.8)$ \\
\hline
\end{tabular}


Table 1. Cont.

\begin{tabular}{lcc}
\hline \multicolumn{1}{c}{ Characteristics } & Mean (SD)/Number (\%) & Mean HGS (lbs.) (95\% CI) \\
\hline Annual income (USD) & & \\
0 to 50,000 & $181(11.7)$ & $54.9(52.5-57.4)$ \\
$>50,000$ to 70,000 & $428(27.7)$ & $55.2(53.6-56.8)$ \\
$>70,000$ to 100,000 & $678(43.9)$ & $56.1(54.8-57.4)$ \\
$>100,000$ & $258(16.7)$ & $56.4(54.4-58.5)$ \\
\hline Level of WTC exposure & & \\
Low & $331(18.0)$ & $53.9(52.1-55.8)$ \\
Intermediate & $1092(59.4)$ & $56.1(55.1-57.1)$ \\
High & $339(18.5)$ & $56.2(54.4-58.0)$ \\
Very high & $75(4.1)$ & $53.6(49.8-57.5)$ \\
\hline WTC-related PTSD & & \\
Probable PTSD (PCL-S $\geq 44)$ with & $200(9.9)$ & $45.9(43.6-48.2)$ \\
depression (PHQ-9 $\geq 10)$ & $104(5.1)$ & $49.2(46.0-52.4)$ \\
Probable PTSD without depression & $1719(85.0)$ & $57.0(56.2-57.8)$ \\
No PTSD or depression & & \\
\hline Self-reported general health & $87(4.4)$ & $61.4(57.9-64.9)$ \\
Excellent & $461(23.1)$ & $59.6(58.1-61.1)$ \\
Very good & $990(49.7)$ & $56.7(55.7-57.7)$ \\
Good & $381(19.1)$ & $49.3(47.6-50.9)$ \\
Fair & $75(3.8)$ & $41.7(38.0-45.5)$ \\
Poor &
\end{tabular}

Total numbers vary between variables because only responders with valid response for each variable are included.

The majority (86\%) were non-Hispanic White (NHW). The average maximal HGS was $55.5 \mathrm{lbs}$. (SD 17.1) with a minimum of $7.5 \mathrm{lbs}$. and a maximum of $109.0 \mathrm{lbs}$. There was no significant difference in HGS and hand dominance. There was a decrease in maximum HGS with increasing age: every year older age was associated with a decrease in maximum HGS by $0.5 \mathrm{lbs} .(p<0.0001)$ (Table 3$)$. Women had mean maximum HGS being more than 21 lbs. lower than men. Among racial/ethnic groups, non-Hispanic Blacks had significantly lower HGS than NHWs. Those who were on disability or on medical leave and those who were retired at the time of the study had significantly lower HGS than those who were working full-time on $9 / 11 / 2001$. Having fair or poor self-reported general health was associated with lower HGS than those with excellent health. Mean HGS of responders with probable PTSD with concurrent depression was $11 \mathrm{lbs}$. lower $(p<0.0001)$, whereas mean HGS of responders with probable PTSD without depression was 8 lbs. lower $(p<0.0001)$ than those without either PTSD or depression.

Table 2. Relationship of handgrip strength (HGS) with independent variables among WTC responders.

\begin{tabular}{lcc}
\hline Characteristics & $\begin{array}{c}\text { Bivariate Regression } \\
\text { Coefficient }(p \text { Value })\end{array}$ & $\begin{array}{c}\text { Multivariable Regression } \\
\text { Coefficient }(p \text { Value })\end{array}$ \\
\hline Age in years & $-0.53(<0.0001)$ & $-0.52(<0.0001)$ \\
\hline Gender & Ref. & Ref. \\
Men & $-21.23(<0.0001)$ & $-21.8(<0.0001)$ \\
Women & Ref. & Ref. \\
\hline Race/ethnicity & $-5.38(0.04)$ & $0.48(0.81)$ \\
Non-Hispanic White & $-3.44(0.11)$ & $-2.23(0.15)$ \\
Non-Hispanic Black & $-3.58(0.89)$ & $-2.28(0.53)$ \\
Hispanic & $-8.26(0.70)$ & $-15.74(0.27)$ \\
Asian & & \\
Other &
\end{tabular}


Table 3. Cont.

\begin{tabular}{|c|c|c|}
\hline Characteristics & $\begin{array}{l}\text { Bivariate Regression } \\
\text { Coefficient ( } p \text { Value) }\end{array}$ & $\begin{array}{l}\text { Multivariable Regression } \\
\text { Coefficient ( } p \text { Value) }\end{array}$ \\
\hline \multicolumn{3}{|l|}{ Hand dominance } \\
\hline Right & Ref. & Ref. \\
\hline Left & $0.09(0.36)$ & $-0.71(0.54)$ \\
\hline Ambidextrous & $3.00(0.22)$ & $3.82(0.05)$ \\
\hline \multicolumn{3}{|l|}{ Marital status } \\
\hline Single & Ref. & Ref. \\
\hline Married & $6.25(0.0007)$ & $0.91(0.65)$ \\
\hline Separated/Divorced/Widowed & $3.94(0.12)$ & $1.46(0.52)$ \\
\hline \multicolumn{3}{|l|}{ Education } \\
\hline Did not finish high school & Ref. & Ref. \\
\hline Graduated high school & $1.96(0.93)$ & $4.90(0.06)$ \\
\hline Some college & $4.06(0.42)$ & $4.42(0.08)$ \\
\hline Undergraduate degree & $6.07(0.09)$ & $4.59(0.08)$ \\
\hline Graduate school & $3.47(0.69)$ & $3.01(0.30)$ \\
\hline \multicolumn{3}{|l|}{ Current employment status } \\
\hline Working full time & Ref. & Ref. \\
\hline Working part time & $-1.84(0.71)$ & $-1.05(0.51)$ \\
\hline Disabled/on medical leave & $-8.13(<0.0001)$ & $-5.04(0.02)$ \\
\hline Retired & $-8.72(<0.0001)$ & $-2.17(0.03)$ \\
\hline Laid off/unemployed & $-7.47(0.17)$ & $-6.41(0.14)$ \\
\hline \multicolumn{3}{|l|}{ Annual income (USD) } \\
\hline 0 to 50,000 & Ref. & Ref. \\
\hline$>50,000$ to 70,000 & $0.25(0.99)$ & $2.55(0.08)$ \\
\hline$>70,000$ to 100,000 & $1.18(0.84)$ & $2.90(0.04)$ \\
\hline$>100,000$ & $1.54(0.78)$ & $4.17(0.01)$ \\
\hline \multicolumn{3}{|l|}{ Level of WTC exposure } \\
\hline Low & Ref. & Ref. \\
\hline Intermediate & $2.17(0.18)$ & $1.60(0.15)$ \\
\hline High & $2.28(0.31)$ & $2.44(0.07)$ \\
\hline Very high & $0.30(0.99)$ & $-3.93(0.08)$ \\
\hline \multicolumn{3}{|l|}{ WTC-related PTSD } \\
\hline $\begin{array}{l}\text { Probable PTSD (PCL-S } \geq 44 \text { ) } \\
\text { with depression (PHQ-9 } \geq 10 \text { ) }\end{array}$ & $-11.11(<0.0001)$ & $-5.33(0.0005)$ \\
\hline $\begin{array}{l}\text { Probable PTSD without } \\
\text { depression }\end{array}$ & $-7.8(<0.0001)$ & $-3.04(0.14)$ \\
\hline No PTSD or depression & Ref. & Ref. \\
\hline \multicolumn{3}{|l|}{ Self-reported general health } \\
\hline Excellent & Ref. & Ref. \\
\hline Very good & $-1.76(0.89)$ & $-0.86(0.69)$ \\
\hline Good & $-4.72(0.08)$ & $-1.72(0.41)$ \\
\hline Fair & $-12.11(<0.0001)$ & $-7.27(0.001)$ \\
\hline Poor & $-19.65(<0.0001)$ & $-15.52(<0.0001)$ \\
\hline
\end{tabular}

Only responders with non-missing responses for each variable are included. Ref.: Reference category.

In multivariate analysis, being in fair or poor health was associated with lower HGS than those with excellent health (Table 3). Responders with both WTC-related probable PTSD and depression, but not those with PTSD without depression, had significantly $(p=0.0005)$ lower mean HGS than those without PTSD or depression. Higher age and female gender remained significantly associated with lower HGS, while race/ethnicity was no longer statistically significant. Mean HGS of those who were disabled or on medical leave and those retired was significantly lower than those working full-time. While income levels had no significant relationship in bivariate analyses, multivariable analysis revealed that HGS of responders with income between US $\$ 70,000$ and 100,000, and those with 
annual income higher than US $\$ 100,000$ were higher by 3lbs. $(p=0.04)$ and $4 \mathrm{lbs} .(p=0.01)$ respectively, in comparison with those earning US\$50,000 or less. Levels of WTC exposure did not show significant relationship with mean HGS in either bivariate or multivariate analyses.

\section{Subdomain Analyses}

On further examination of the PTSD domains (results not shown in table), higher severity of re-experiencing symptoms was significantly associated with lower HGS while all other domains showed no such relationship after controlling for other domains and all other covariates. Increase in re-experiencing score by one point was associated with a decrease in HGS by $0.45 \mathrm{lbs}$. ( $p=0.0032)$; since those with the worst symptom severity have symptom scores 15 or 20 points above those with no symptoms, this translates into substantial and large differences in HGS.

\section{Discussion}

Lower HGS, after adjusting for sex, is increasingly seen as a biomarker of aging [5,14-17]. Our study similarly revealed that max HGS was associated with older age, supporting this view. Additionally, our study revealed that those with probable WTC-PTSD, with and without concomitant depression had significantly lower maximal HGS than those without either PTSD or depression. Examining individual PCL domain scores revealed that the re-experiencing symptom cluster was specifically associated with HGS, a finding that remained significant even after adjusting for covariates and other PTSD symptoms.

A remarkable finding was that the mean HGS of WTC responders in this study, many of whom were in the law enforcement and are usually shown to have "healthy worker" effects, is not as high as might typically be expected. Based on normative data published by Mathiowetz et al., the mean HGS of adults in the 50-54 year-old age range-the mean age of our sample-was 102-114 lbs. for men and 57-66 lbs. for women [18]. Among respondents to the Health and Retirement Survey in 2006-2012, the mean HGS of 55-59-year-old men was 38-43 kg or 84-95 lbs., while it was $22-28 \mathrm{~kg}$ or 49-62 lbs. for women [17]. By comparison, the mean HGS was $57.4 \mathrm{lbs}$. for men and $36.1 \mathrm{lbs}$. for women in our sample. Unlike our sample, which comprised of responders with varying degrees of exposure to the WTC trauma, both of the aforementioned studies involved civilian populations. Moreover, adjustable-handle Jamar ${ }^{\circledR}$ dynamometer and Smedley ${ }^{\circledR}$ spring-type dynamometer were used as opposed to the Vernier dynamometer used in our study. Future research needs to examine whether lower HGS in our cohort can be attributed to their exposure to the traumatic WTC experiences, and/or due to differences in the instruments used. Our findings should be interpreted with caution, however, as lower HGS among WTC responders may also be attributed to PTSD-related weakness, easy fatigability, and neurasthenia, as evidenced from symptoms experienced by war veterans [19].

Our finding of lower maximal HGS among WTC responders with WTC-related PTSD and depression are along the lines of those reported by Clouston et al. when current PTSD was associated with a two-fold higher risk of functional limitations as indicated by Short Physical Performance Battery (SPPB) scores of 9 or lower [9]. Specifically, current PTSD showed strong adjusted associations with slower walking speeds $(<0.8 \mathrm{~m} / \mathrm{s})$, slower chair-rise speed $(<0.39$ rises $/ \mathrm{s})$, and balance problems. Previous research by Keller-Ross and colleagues (2014) found that veterans with PTSD have greater fatigability as well as greater fluctuations in force exerted by their handgrip muscles [20]. It is possible that PTSD affects physical functioning and HGS through similar pathways. Furthermore, depending on their mental health and motivation, not all responders may have exerted adequate effort when asked to take the HGS test. However, this concern may have been partially addressed as our analyses took depressive symptoms, in addition to symptoms of PTSD, into consideration. It is notable that of all the PTSD domains, re-experiencing symptoms emerged as most significantly associated with lower HGS. This is comparable to prior work where re-experiencing symptoms were found to be consistently associated with cognitive impairment among WTC responders [8]. Re-experiencing symptoms that include sudden intrusive memories of the traumatic event, nightmares, flashbacks, and other feelings 
of distress, have been noted to be early markers of mental pathology [21,22]. Findings from our current study suggest that these symptoms can affect individuals both physically and mentally.

Future research may focus on the association between HGS and PTSD symptoms among populations with other traumatic experiences. There is some evidence that resistance training can lead to better cognitive functioning among the elderly through a posited reversal of age-related deterioration of the brain white matter [23,24]. It will be important to complete the clinical picture by examining other trauma-related symptoms, including depression. It might be useful to explore whether HGS improvement may help address some PTSD symptoms, in addition to the existing modes of management. It is also possible that changes in HGS precede changes in PTSD symptoms or higher HGS at baseline protects against psychological symptoms, as similar hypotheses have been postulated for cognitive decline as well. The integrity of white matter has been linked to optimum physical and mental functioning; therefore, the same underlying mechanisms could predispose responders to lower HGS as well as PTSD and depression symptoms.

\section{Limitations}

This is the first study to examine HGS in a large sample of WTC responders, and the first to report associations between PTSD and HGS. A key limitation of this study is its cross-sectional nature, limiting our ability to investigate possible reverse causation. Since we found associations between PTSD symptoms measured at program enrollment visits, which occurred on average 8-10 years before HGS was assessed, the potential for reverse causation is greatly reduced. However, the relationship could be bidirectional, and a potential common pathology that predisposes to both PTSD symptoms and muscular weakness might be the most valuable take-away from our study. It is, therefore, critical that future work examine associations between PTSD symptoms and changes to HGS over time. The generalizability of this study to the general population, given that responders in this study are residents of Long Island, NY, with a majority being highly educated White males. The WTC responders were exposed to a very unique event-the $9 / 11$ attacks and its aftermath-which may not result in similar physical exposures and, therefore, concomitant PTSD complexity, severity, or chronicity that is similar to symptoms experienced after other traumatic exposures. This study does not, as well, consider the impact of childhood exposures to stressful events though such events have been found to worsen mental health [25]. Nevertheless, many of the findings among veterans and healthy adults from different countries provide similar overall conclusions.

\section{Conclusions}

This, to our knowledge, is the first study examining the association of HGS with PTSD with or without coexisting depressive symptoms in a large cohort exposed to a severe traumatic event. Our finding that PTSD symptoms in general, and re-experiencing in particular, are associated with lower HGS fifteen years after a significant traumatic event could have clinical implications in the potential for HGS to be a "biomarker" of aging in the context of severe and chronic PTSD. Furthermore, and similar to prior findings, this points out to the potential for interventions targeting physical strength also having a beneficial effect on responders' mental health, or vice versa.

Author Contributions: The research question was formulated by S.M. and S.C. The study was conceptualized and implemented by S.C. and B.L. Methodology was developed by S.C., E.B., R.K., and B.L. Resources were managed by S.C. and B.L. Data management and data analysis was done by S.M. and S.C. The article was drafted initially by S.M. and the initial draft was revised by S.C., E.B., R.K., and B.L. provided feedback and helped to improve the manuscript. S.M. was responsible for initial submission, making revisions according to comments by the journal editor and reviewers, and for resubmission. S.C., E.B., and B.L. provided inputs for addressing the reviewers' comments and helped in the revision process.

Funding: Funding for this study was provided by the National Institutes of Health (R01 AG049953; PI: Clouston), and by the Centers for Disease Control and Prevention's National Institute of Occupational Safety and Health to administer the monitoring survey and diagnose and treat World Trade Center (WTC)-related diseases (CDC200-2011-39361). 
Conflicts of Interest: The authors declare no conflict of interest. The funders had no role in the design of the study; in the collection, analyses, or interpretation of data; in the writing of the manuscript, or in the decision to publish the results.

\section{References}

1. Massy-Westropp, N.M.; Gill, T.K.; Taylor, A.W.; Bohannon, R.W.; Hill, C.L. Hand grip strength: Age and gender stratified normative data in a population-based study. BMC Res. Notes 2011, 4, 127. [CrossRef]

2. Ling, C.H.; Taekema, D.; de Craen, A.J.; Gussekloo, J.; Westendorp, R.G.; Maier, A.B. Handgrip strength and mortality in the oldest old population: The Leiden 85-plus study. Can. Med. Assoc. J. 2010, 182, 429-435. [CrossRef] [PubMed]

3. Taekema, D.G.; Gussekloo, J.; Maier, A.B.; Westendorp, R.G.; de Craen, A.J. Handgrip strength as a predictor of functional, psychological and social health. A prospective population-based study among the oldest old. Age Ageing 2010, 39, 331-337. [CrossRef] [PubMed]

4. Fukumori, N.; Yamamoto, Y.; Takegami, M.; Yamazaki, S.; Onishi, Y.; Sekiguchi, M.; Otani, K.; Konno, S.; Kikuchi, S.; Fukuhara, S. Association between hand-grip strength and depressive symptoms: Locomotive syndrome and health outcomes in aizu cohort study (LOHAS). Age Ageing 2015, 44, 592-598. [CrossRef]

5. Lino, V.T.S.; Rodrigues, N.C.P.; O’Dwyer, G.; de Noronha Andrade, M.K.; Mattos, I.E.; Portela, M.C. Handgrip strength and factors associated in poor elderly assisted at a primary care unit in Rio de Janeiro, Brazil. PLOS ONE 2016, 11, e0166373. [CrossRef]

6. Firth, J.; Firth, J.A.; Stubbs, B.; Vancampfort, D.; Schuch, F.B.; Hallgren, M.; Veronese, N.; Yung, A.R.; Sarris, J. Association between Muscular Strength and cognition in people with major depression or bipolar disorder and healthy controls. JAMA Psychiatry 2018, 75, 740-746. [CrossRef]

7. Firth, J.; Stubbs, B.; Vancampfort, D.; Firth, J.A.; Large, M.; Rosenbaum, S.; Hallgren, M.; Ward, P.B.; Sarris, J.; Yung, A.R. Grip strength is associated with cognitive performance in schizophrenia and the general population: A UK biobank study of 476,559 participants. Schizophr. Bull. 2018, 44, 728-736. [CrossRef] [PubMed]

8. Clouston, S.A.; Kotov, R.; Pietrzak, R.H.; Luft, B.J.; Gonzalez, A.; Richards, M.; Ruggero, C.J.; Spiro, A., III; Bromet, E.J. Cognitive impairment among world trade center responders: Long-term implications of re-experiencing the 9/11 terrorist attacks. Alzheimers Dement. 2016, 4, 67-75. [CrossRef] [PubMed]

9. Clouston, S.A.; Guralnik, J.M.; Kotov, R.; Bromet, E.J.; Luft, B.J. Functional limitations among responders to the world trade center attacks 14 years after the disaster: Implications of chronic posttraumatic stress disorder. J. Trauma. Stress 2017, 30, 443-452. [CrossRef] [PubMed]

10. Dasaro, C.R.; Holden, W.L.; Berman, K.D.; Crane, M.A.; Kaplan, J.R.; Lucchini, R.G.; Luft, B.J.; Moline, J.M.; Teitelbaum, S.L.; Tirunagari, U.S.; et al. Cohort profile: World trade center health program general responder cohort. Int. J. Epidemiol. 2015, 46, e9. [CrossRef] [PubMed]

11. Blanchard, E.B.; Jones-Alexander, J.; Buckley, T.C.; Forneris, C.A. Psychometric properties of the PTSD Checklist (PCL). Behav. Res. Ther. 1996, 34, 669-673. [CrossRef]

12. Wilkins, K.C.; Lang, A.J.; Norman, S.B. Synthesis of the psychometric properties of the PTSD checklist (PCL) military, civilian, and specific versions. Depress. Anxiety 2011, 28, 596-606. [CrossRef]

13. Wisnivesky, J.P.; Teitelbaum, S.L.; Todd, A.C.; Boffetta, P.; Crane, M.; Crowley, L.; de la Hoz, R.E.; Dellenbaugh, C.; Harrison, D.; Herbert, R.; et al. Persistence of multiple illnesses in world trade center rescue and recovery workers: A cohort study. Lancet 2011, 378, 888-897. [CrossRef]

14. Koopman, J.J.; van Bodegom, D.; van Heemst, D.; Westendorp, R.G. Handgrip strength, ageing and mortality in rural Africa. Age Ageing 2015, 44, 465-470. [CrossRef] [PubMed]

15. Ong, H.L.; Abdin, E.; Chua, B.Y.; Zhang, Y.; Seow, E.; Vaingankar, J.A.; Chong, S.A.; Subramaniam, M. Hand-grip strength among older adults in Singapore: A comparison with international norms and associative factors. BMC Geriatr. 2017, 17, 176. [CrossRef] [PubMed]

16. Hamasaki, H.; Kawashima, Y.; Katsuyama, H.; Sako, A.; Goto, A.; Yanai, H. Association of handgrip strength with hospitalization, cardiovascular events, and mortality in Japanese patients with type 2 diabetes. Sci. Rep. 2017, 7, 7041. [CrossRef] [PubMed]

17. Sanderson, W.C.; Scherbov, S. Measuring the speed of aging across population subgroups. PLoS ONE 2014, 9, e96289. [CrossRef] [PubMed] 
18. Mathiowetz, V.; Kashman, N.; Volland, G.; Weber, K.; Dowe, M.; Rogers, S. Grip and pinch strength: Normative data for adults. Arch. Phys. Med. Rehabil. 1985, 66, 69-74. [PubMed]

19. Hyams, K.C.; Wignall, F.S.; Roswell, R. War syndromes and their evaluation: From the US civil war to the Persian gulf war. Ann. Intern. Med. 1996, 125, 398-405. [CrossRef] [PubMed]

20. Keller-Ross, M.L.; Schlinder-Delap, B.; Doyel, R.; Larson, G.; Hunter, S.K. Muscle fatigability and control of force in men with posttraumatic stress disorder. Med. Sci. Sports Exerc. 2014, 46, 1302-1313. [CrossRef]

21. Chaudieu, I.; Norton, J.; Ritchie, K.; Birmes, P.; Vaiva, G.; Ancelin, M.L. Late-life health consequences of exposure to trauma in a general elderly population: The mediating role of reexperiencing posttraumatic symptoms. J. Clin. Psychiatry 2011, 72, 929-935. [CrossRef] [PubMed]

22. Lawrence-Wood, E.; Van Hooff, M.; Baur, J.; McFarlane, A.C. Re-experiencing phenomena following a disaster: The long-term predictive role of intrusion symptoms in the development of post-trauma depression and anxiety. J. Affect. Disord. 2016, 190, 278-281. [CrossRef] [PubMed]

23. Cassilhas, R.C.; Viana, V.A.; Grassmann, V.; Santos, R.T.; Santos, R.F.; Tufik, S.; Mello, M.T. The impact of resistance exercise on the cognitive function of the elderly. Med. Sci. Sports Exerc. 2007, 39, 401-1407. [CrossRef] [PubMed]

24. Suo, C.; Singh, M.F.; Gates, N.; Wen, W.; Sachdev, P.; Brodaty, H.; Saigal, N.; Wilson, G.C.; Meikeljohn, J.; Singh, N.; et al. Therapeutically relevant structural and functional mechanisms triggered by physical and cognitive exercise. Mol. Psychiatry 2016, 21, 1633-1642. [CrossRef]

25. Mukherjee, S.; Clouston, S.; Bromet, E.; Leibowitz, G.S.; Scott, S.B.; Bernard, K.; Kotov, R.; Luft, B.J. Past experiences of getting bulled and assaulted and posttraumatic stress disorder (PTSD) after a severe traumatic event in adulthood: A study of World Trade Center (WTC) responders. J. Aggress. Maltreat. Trauma 2019, 1-19. [CrossRef]

(C) 2019 by the authors. Licensee MDPI, Basel, Switzerland. This article is an open access article distributed under the terms and conditions of the Creative Commons Attribution (CC BY) license (http:/ / creativecommons.org/licenses/by/4.0/). 